\title{
Differential Response of Cortical Plate and Ventricular Zone Cells to GABA as a Migration Stimulus
}

\author{
Toby N. Behar, Anne E. Schaffner, Catherine A. Scott, Casey O'Connell, and Jeffery L. Barker \\ Laboratory of Neurophysiology, National Institute of Neurological Disorders and Stroke, National Institutes of Health, \\ Bethesda, Maryland 20892
}

\begin{abstract}
A microdissection technique was used to separate differentiated cortical plate (cp) cells from immature ventricular zone cells (vz) in the rat embryonic cortex. The cp population contained $>85 \%$ neurons $\left(\mathrm{TUJ}^{+}\right)$, whereas the $\mathrm{vz}$ population contained $\sim 60 \%$ precursors (nestin ${ }^{+}$only). The chemotropic response of each population was analyzed in vitro, using an established microchemotaxis assay. Micromolar GABA (1-5 $\mu \mathrm{M})$ stimulated the motility of $\mathrm{cp}$ neurons expressing glutamic acid decarboxylase (GAD), the rate-limiting enzyme in GABA synthesis. In contrast, femtomolar GABA (500 fM) directed a subset of $\mathrm{GAD}^{-}$vz neurons to migrate. Thus, the two GABA concentrations evoked the motility of phenotypically distinct
\end{abstract}

populations derived from different anatomical regions. Pertussis toxin (PTX) blocked GABA-induced migration, indicating that chemotropic signals involve G-protein activation. Depolarization by micromolar muscimol, elevated $\left[\mathrm{K}^{+}\right]_{0}$, or micromolar glutamate arrested migration to GABA or GABA mimetics, indicating that migration is inhibited in the presence of excitatory stimuli. These results suggest that GABA, a single ligand, can promote motility via G-protein activation and arrest attractantinduced migration via $\mathrm{GABA}_{\mathrm{A}}$ receptor-mediated depolarization.

Key words: development; chemotaxis; cortex; G-protein; depolarization; neuron; migration
GABA is a fast-acting inhibitory neurotransmitter in the mature mammalian CNS. During embryonic development GABA is expressed transiently in many regions of the CNS (Lauder et al., 1986; Ma et al., 1992; Schaffner et al., 1993), suggesting that it may have a functional role in development. In vivo, GABA is detected near the target destinations of migratory neurons; in vitro, it has been shown to promote embryonic nerve cell movement (Behar et al., 1994, 1996). Together, these results suggest that GABA may act as a chemoattractant, guiding newly generated neurons toward their final target positions.

Previously, we used an in vitro microchemotaxis assay to demonstrate that two distinct concentrations of GABA evoke the motility of rat embryonic neurons acutely dissociated from the embryonic day 18 (E18) cortex (Behar et al., 1996). Micromolar concentrations stimulate chemokinesis (random motility), whereas femtomolar GABA levels induce chemotaxis (directed migration). The majority of cells exhibiting chemokinetic responses to micromolar GABA contains glutamic acid decarboxylase (GAD), the enzyme that synthesizes GABA from glutamate. In contrast, the population exhibiting chemotaxis to femtomolar GABA is not enriched in $\mathrm{GAD}^{+}$cells, indicating that each GABA concentration stimulates motility in a distinct subpopulation of cortical neurons.

During development, neurons are generated in proliferative regions adjacent to the ventricle. After terminal mitosis, newly generated neurons migrate away from the ventricular zone, traverse through the intermediate zone, and enter the cortical plate where they organize into layers and differentiate further (Jacob-

\footnotetext{
Received March 17, 1998; revised May 22, 1998; accepted May 29, 1998.

Correspondence should be addressed to Dr. T. N. Behar, Laboratory of Neurophysiology, National Institute of Neurological Disorders and Stroke, National Institutes of Health, Building 36, Room 2C02, 36 Convent Drive, Bethesda, MD 20892-4066.

Copyright (ㄷ) 1998 Society for Neuroscience $\quad 0270-6474 / 98 / 186378-10 \$ 05.00 / 0$
}

son, 1991). Because GABAergic cells are present in both the subventricular zone and the cortical plate at E18 (Behar et al., 1996), in the present study we sought to identify the anatomical origin of the $\mathrm{GAD}^{+}$and $\mathrm{GAD}^{-}$populations that migrate to GABA in vitro. We used a microdissection technique similar to that described by Frantz and McConnell (1996), which effectively separates the cortical plate (cp) cells from the ventricular zone (vz) cells. $\mathrm{Vz}$ and cp cell motility responses to each chemotropic concentration of GABA were analyzed.

A distinguishing feature of the microchemotaxis assay is the "bell-shaped" dose-response curve to chemoattractants that many different cell types, including leukocytes (Geiser et al., 1993), smooth muscle cells (Higashiyama et al., 1993), and microglia (Yao et al., 1990), typically exhibit. The nature of the bell-shaped dose-response curve suggests that a single attractant mediates both start and stop motility signals. Although very low concentrations fail to promote cell movement, optimal concentrations stimulate migration, and excessive levels of attractant inhibit further motility. This may reflect a physiological mechanism of attractants. In vivo, low concentrations of attractants would stimulate cells to begin migrating. However, as cells approach their final positions, they would encounter increasing levels of the attractant. The high levels encountered near the target destination actually may signal the cells to stop moving.

The mechanisms by which a single attractant mediates both start and stop motility signals are unknown. In the present study we have analyzed the initial signaling mechanisms that promote or inhibit neuronal motility responses to GABA.

\section{MATERIALS AND METHODS}

Dissection and dissociation. Cortical cells from embryonic Sprague Dawley rat pups at E18 and E19 were analyzed because on these days we found peak levels of GABA-induced migration (Behar et al., 1996). Embryonic age was determined by the appearance of a vaginal plug (day 1) and measurement of crown-rump length (Schaffner et al., 1993). 
Dams were euthanized with $\mathrm{CO}_{2}$, and embryos were removed by cesarean section. Brains from littermates were removed and placed into cold $\left(4^{\circ} \mathrm{C}\right)$ Leibovitz's L-15 medium (Life Technologies, Grand Island, NY) supplemented with $0.1 \mathrm{mg} / \mathrm{ml}$ bovine serum albumin (BSA; Sigma, St. Louis, MO) and $16 \mathrm{~mm}$ glucose. A McIlwaine tissue chopper (Brinkman, Westbury, NY) was used to prepare $350 \mu \mathrm{m}$ coronal slices of the telencephalon. Slices were transferred to a dish containing the L-15 medium, and the slices were teased apart and cleaned of meninges under a dissecting microscope. Individual slices were transferred to a clean 35 $\mathrm{mm}$ dish and covered with a drop of the $\mathrm{L}-15$ medium. The slices were microdissected through the cortical intermediate zone (see Fig. $2 A, B$ ), which divided the cortex into two tissue segments designated as the $\mathrm{cp}$ and the vz (see Fig. $2 B$ ). Tissue designated $\mathrm{cp}$ included the cortical plate, subplate (sp), and the upper half of the intermediate zone (iz). Tissue designated vz included the ventricular zone, subventricular zone (svz), and the lower half of the iz.

Whole cortex or tissue segments from the vz or cp regions were dissociated enzymatically into single-cell suspensions with papain. Briefly, the tissue or segments from a single region were pooled and incubated with gentle rocking at $37^{\circ} \mathrm{C}$ for $10-15$ min in Earle's balanced salt solution (EBSS) containing $20 \mathrm{U} / \mathrm{ml}$ papain (Worthington Biochemical, Freehold, NJ), 0.005\% DNase (Boehringer Mannheim, Indianapolis, IN), $0.5 \mathrm{~mm}$ EDTA, and $1 \mathrm{~mm}$ L-cysteine. Tissue was triturated through a $10 \mathrm{ml}$ pipette, spun at $300 \times g$ for $5 \mathrm{~min}$, and resuspended in EBSS containing $1 \mathrm{mg} / \mathrm{ml} \mathrm{BSA}$ and $1 \mathrm{mg} / \mathrm{ml}$ ovomucoid trypsin inhibitor (Sigma). The cell suspension was layered over $5 \mathrm{ml}$ of EBSS containing $10 \mathrm{mg} / \mathrm{ml}$ each of BSA and trypsin inhibitor and was centrifuged at room temperature at $80 \times g$ for $7 \mathrm{~min}$. Cells were resuspended in EBSS plus 16 $\mathrm{mm}$ glucose at a concentration of $10^{6}$ cells $/ \mathrm{ml}$ for the migration studies. For quantitative analysis using immunocytochemistry, $2.5 \times 10^{5}$ cells were seeded onto $35 \mathrm{~mm}$ NUNC (Naperville, IL) culture dishes precoated with poly-D-lysine [ $>450,000$ molecular weight (MW); $20 \mu \mathrm{g} / \mathrm{ml}]$ (Collaborative Research, Bedford, MA) and were allowed to adhere onto the dishes for $1 \mathrm{hr}$ at $37^{\circ} \mathrm{C}$.

Quantitative analysis of TUJ1 and nestin staining in dissociates. Adherent cells on culture dishes were fixed for $30 \mathrm{~min}$ in $4 \%$ paraformaldehyde (PF) and washed in PBS, pH 7.2. Cells were incubated at $4^{\circ} \mathrm{C}$ overnight in a mixture of rabbit anti-nestin antibody (1:1500; gift of Dr. R. McKay, National Institute of Neurological Diseases and Stroke, National Institutes of Health, Bethesda, MD) and TUJ1 antibody (1:400; gift of Dr. Anthony Frankfurter, Biology Department, University of Virginia, Charlottesville, VA). The cells were washed three times in PBS and then incubated for $1 \mathrm{hr}$ at $21^{\circ} \mathrm{C}$ in appropriate secondary antibodies (donkey anti-rabbit FITC and rat anti-mouse TRITC, 1:50; Jackson ImmunoResearch, West Grove, PA). PBS supplemented with $0.05 \%$ saponin and $0.1 \%$ BSA was used as the antibody diluent. Controls were incubated in buffer only without primary antibody, followed by incubation in secondary antiserum only. Control cells incubated in secondary antibody alone did not fluoresce. Immunolabeled cells were examined on a Zeiss Axiophot microscope (Oberkochen, Germany) equipped with epifluorescence and the appropriate filters for the visualization of fluorescein and rhodamine. The percentage of positively stained cells was determined by dividing the number of fluorescently labeled cells in a field by the total number of cells in the same field (visualized under phase-contrast with a $40 \times$ water immersion objective). Ten random fields were counted per dish, averaging 1000 cells per plate. Plates were run in duplicate for each experiment. Data were subjected to ANOVA to determine variation within groups. No significant difference between replicate plates was detected. Each region was analyzed in a minimum of five separate experiments.

Cell migration. Chemotropic responses of $\mathrm{vz}$ and $\mathrm{cp}$ cells to GABA were assessed with the use of a microchemotaxis chamber (Neuroprobe, Cabin John, MD). Details of the microchemotaxis assay are described elsewhere (Behar et al., 1994). Chemoattractants and cells used in the assay were diluted in EBSS with $16 \mathrm{~mm}$ glucose. The optimal concentrations of the attractants ( $5 \mu \mathrm{M}$ and $500 \mathrm{fm}$ GABA) for eliciting chemotropic responses in embryonic rat cortical cells were determined previously (Behar et al., 1996). Briefly, the lower wells of the chemotaxis chamber were filled with $29 \mu \mathrm{l}$ of attractant. The attractants were covered with a polycarbonate filter containing $8 \mu \mathrm{m}$ pores (precoated with 30 $\mu \mathrm{g} / \mathrm{ml}$ poly-D-lysine; MW $>450,000$ ) (Collaborative Research). The upper portion of the chamber, containing 48 wells, was placed over the filter, and each well was filled with $50 \mu \mathrm{l}$ of the cell suspension containing $10^{6} \mathrm{cells} / \mathrm{ml}$ in $\operatorname{EBSS}(50,000$ cells $)$.

In studies involving the pharmacological inhibition of evoked migra- tion, GABA or a conformationally restricted analog, cis-4-aminocrotonic acid (CACA), was mixed with potential inhibitors (final concentrations: $10 \mu \mathrm{M}$ bicuculline, $10 \mu \mathrm{M}$ picrotoxin, $100 \mathrm{nM}-10 \mu \mathrm{M}$ muscimol, $10 \mathrm{pM}-10$ $\mu \mathrm{M}$ glutamate, or EBSS containing $7.5-50 \mathrm{~mm} \mathrm{~K}^{+}$). In one set of studies, $\mathrm{cp}$ and vz cells were preincubated for $20 \mathrm{~min}$ at $21^{\circ} \mathrm{C}$ in pertussis toxin (PTX; $1 \mu \mathrm{g} / \mathrm{ml}$ in EBSS) before incubation in the chambers in the presence of attractants.

Cells were allowed to migrate for $18 \mathrm{hr}$ at $37^{\circ} \mathrm{C}$ in humidified air with $9 \% \mathrm{CO}_{2}$. Migrated cells on the lower side of the filter were fixed in $4 \%$ PF with $0.1 \%$ glutaraldehyde and stained in $0.1 \%$ cresyl violet. The membranes were mounted cell-side up onto $2 \times 3$ inch glass slides, allowed to air dry, and covered with immersion oil.

Migrated cells were counted by using oil immersion $16 \times$ or $40 \times$ Zeiss Planapo objectives on a Zeiss photomicroscope. Each chemoattractant condition was run in triplicate wells. Three to five fields of stained cells were counted for each well, and the average number of migrated cells/ $\mathrm{mm}^{2}$ for each attractant condition was calculated. In every assay, spontaneous random motility was quantitated by exposing cells in buffer only. Spontaneous migration ranged between 0 and 6 cells $/ \mathrm{mm}^{2}$. For the dose-response studies, migratory responses of $50 \mathrm{cells} / \mathrm{mm}^{2}$ or more were arbitrarily considered significant, because this was $\sim 10$ times greater than the rates of spontaneous migration. Illustrations of doseresponse studies are representative plots from individual experiments (dose-response studies, $n=8 ; \mathrm{K}^{+}$titration, $n=3$; response by region, $n=3$ ). For the inhibition studies the data were normalized across trials as follows: for each trial with an inhibitor, the number of cells $/ \mathrm{mm}^{2}$ that migrated in the presence of the inhibitor was divided by the number of cells $/ \mathrm{mm}^{2}$ that migrated in the presence of attractant only and multiplied by 100 (percentage of control migration). Then the percentage of control migration was averaged across replicate trials for each inhibitor (muscimol, $n=5$; bicuculline, $n=5$; picrotoxin, $n=5$; muscimol plus bicuculline, $n=3$; PTX, $n=3$ ).

The level of maximum migratory response to GABA or CACA varied among experimental trials. This observed variation in functional response appears to be characteristic of the in vitro microchemotaxis assay, because various non-neuronal cells such as microglia (Yao et al., 1990), glial cells (Armstrong et al., 1990), and neutrophils (Harvath et al., 1980) exhibit similar variations in their maximum migration. Within each experimental trial, however, migratory responses to GABA or CACA $\left(\right.$ cells $\left./ \mathrm{mm}^{2}\right)$ were always highly significant when compared with control levels of spontaneous motility ( $p<0.01$; ANOVA, followed by Fisher's protected least significant difference test).

Bromodeoxyuridine (BrdU) incorporation of dissociated cells. In some of the in vitro microchemotaxis studies, $50 \mu \mathrm{g} / \mathrm{ml} \mathrm{BrdU}$ was added to the cell suspension at the beginning of the incubation period. After migrating in the chambers, the responding cells were fixed for $30 \mathrm{~min}$ in $4 \% \mathrm{PF}$, stained with cresyl violet, and then immunostained with peroxidaselabeled anti-BrdU antibody (Becton Dickinson, San Jose, CA) and diaminobenzidine (DAB) substrate.

In some studies the starting populations of adherent cells or migrated cells were analyzed for neurofilament (NF) or GAD67 expression after fixation and cresyl violet staining. Peroxidase immunolabeling with DAB was used to stain the migrated cells adhering to the filter, because the filters used in the chemotaxis assay autofluoresce. NF expression was used to identify neurons in the migrated population, because the TUJ1 antibody produced weak immunostaining coupled with high nonspecific background staining on the filters when used in conjunction with peroxidase-labeled secondary antisera and DAB. For GAD and NF labeling, migrated cells were fixed, stained with cresyl violet, rinsed in buffer, and then incubated for $2 \mathrm{hr}$ at room temperature in anti-NF (tissue culture supernatant, 1:8) or in rabbit anti-GAD67 (1:100; gift from Dr. A. Lernmark, University of Washington School of Medicine, Seattle, WA) in PBS with $0.1 \%$ Triton X-100. The cells were washed three times and incubated in peroxidase-conjugated goat anti-mouse IgM or in donkey anti-rabbit IgG (1:40; Jackson ImmunoResearch) for $1 \mathrm{hr}$ at room temperature. Immunoreaction product was visualized via DAB. Cresyl violet staining enabled the visualization of total cells, whereas the immunostaining appeared as a brown immunoreaction product that accumulated in the soma and neurites. Cells were counted under bright field, using $25 \times$ Planapo objectives.

Viability of cells in the presence of inhibitors. The starting population of cells, suspended in EBSS with $16 \mathrm{~mm}$ glucose, was seeded onto $35 \mathrm{~mm}$ NUNC culture dishes precoated with poly-D-lysine ( $>450,000 \mathrm{MW} ; 20$ $\mu \mathrm{g} / \mathrm{ml}$ ) (Collaborative Research) at $2.5 \times 10^{5}$ cells $/$ dish. Cells were allowed to adhere onto the dishes for $1 \mathrm{hr}$ at $37^{\circ} \mathrm{C}$ and then were fed with 


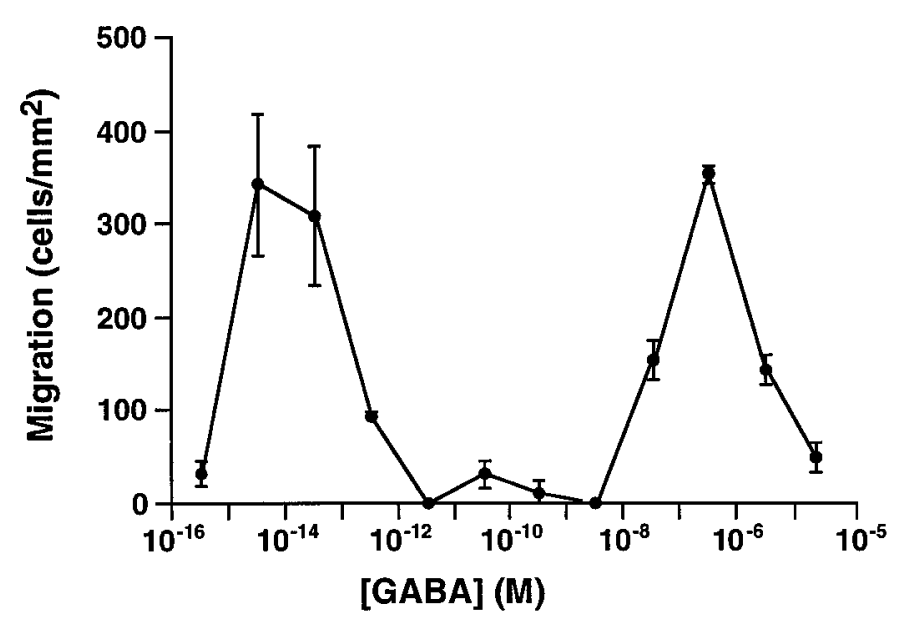

Figure 1. Chemotropically active concentration ranges of GABA form bell-shaped dose-response curves. Shown is GABA-induced migration of E18 cells dissociated from the whole cortex. At E18 the dose-response curve of cells isolated from the whole cortex is bimodal. Femtomolar GABA and micromolar GABA induce similar numbers of cells to migrate. Error bars indicate SEM.

either control medium (EBSS with $16 \mathrm{~mm}$ glucose) or EBSS with glucose containing attractant $(5 \mu \mathrm{M}$ GABA $)$ plus inhibitor $(1 \mu \mathrm{g} / \mathrm{ml}$ PTX, 10 pM-10 $\mu$ M glutamate, $10 \mathrm{~mm} \mathrm{~K}^{+}, 20 \mathrm{mM} \mathrm{K}^{+}$, and $50 \mathrm{mM} \mathrm{K}^{+}$). Cells were incubated in the presence of the inhibitors for $18 \mathrm{hr}$ at $37^{\circ} \mathrm{C}$; then the viability of the cells was determined by using trypan blue exclusion. In control media the cell viability at $18 \mathrm{hr}$ was $95.9 \pm 2.3 \%$. In the presence of each inhibitor the viability equaled or surpassed that of the controls (PTX, $99.0 \pm 1.2 \%$; $10 \mu \mathrm{M}$ glutamate, $98.9 \pm 3.1 \%$; $10 \mathrm{nM}$ glutamate, $97.4 \pm 1.0 \% ; 10$ pM glutamate, $96.7 \pm 2.6 \% ; 10 \mathrm{~mm} \mathrm{~K}^{+}, 97.5 \pm 0.9 \% ; 20$ $\mathrm{mM} \mathrm{K}^{+}, 96.5 \pm 3.1 \%$; $50 \mathrm{mM} \mathrm{K}^{+}, 98.8 \pm 1.0 \%$ ).

\section{RESULTS}

\section{Effective chemotropic concentration ranges of GABA form bell-shaped dose-response curves}

Cells dissociated from the whole cortex at E18 exhibited dosedependent migratory responses to GABA (Fig. 1). At this age two discrete concentration ranges of GABA elicited cell motility. Both low (5-500 fM) and high (50 nM-5 $\mu \mathrm{M})$ ranges of concentration stimulated similar numbers of cells to migrate. Dilutions of GABA between these ranges did not evoke significant $(>50$ cells $/ \mathrm{mm}^{2}$ ) migration, and higher GABA levels failed to elicit motility. Thus, each chemotropically active concentration range formed a bell-shaped curve (Fig. 1). Previous studies have demonstrated that the low effective chemotropic levels of GABA (femtomolar) elicit the migration of $\mathrm{GAD}^{-}$cortical cells, whereas micromolar GABA evokes motility in a $\mathrm{GAD}^{+}$population (Behar et al., 1996). Thus, each effective range of GABA influences the movement of distinct cortical cell populations.

\section{Vz and $c p$ dissociates contain different populations of cells}

Immunocytochemistry was used to characterize the lineagerelated epitopes of cells dissociated from the $\mathrm{vz}$ and $\mathrm{cp}$ regions at E18. Acutely dissociated cells were double-labeled with the neuronal marker TUJ1 (Lee et al., 1990) and with anti-nestin antibody, which labels precursor cells and radial glia (Tohyama et al., 1992) (Fig. 2C,D). The results of the immunolabeling, which represents the average of seven separate trials, are presented in Table 1. Approximately two-thirds of the vz cells expressed only nestin $(64.4 \%)$, indicating that they were progenitors or radial glia. The remaining vz cells were TUJ1 ${ }^{+}$neurons $(35.6 \% \pm 7.3)$.
More than one-half of the neurons from the vz also expressed nestin $\left(\mathrm{TUJ} 1^{+} /\right.$nestin $\left.^{+}\right)$, indicating that they most probably were newly differentiated. Thus, within the vz preparation $\sim 83 \%$ of all cells were nestin ${ }^{+}$. In contrast, only $23.2 \%( \pm 5.6)$ of the cells in the cp preparation labeled with the anti-nestin antibody; of these, only $12.4 \%$ are presumed to be precursors (nestin ${ }^{+} / \mathrm{TUJ}^{-}{ }^{-}$). The majority of cp cells $(87.7 \pm 1.8 \%)$ was $\mathrm{TUJ} 1^{+}$, indicating that most of the cells in the cp preparation were neuronal. Within the cp preparation a minority of the neurons (10.7\%) also expressed nestin.

\section{Femtomolar GABA induces vz cells to migrate, whereas micromolar GABA stimulates $\mathbf{c p}$ cell motility}

Previously, we reported that, in vitro, two distinctly different concentration ranges of GABA evoked the motility of embryonic rat cortical neurons acutely dissociated from the whole cortex at E18 (Behar et al., 1996). Characterization of the migratory responses revealed that femtomolar GABA induced directed migration (chemotaxis), whereas micromolar GABA stimulated increased random motility (chemokinesis). Here, we sought to identify the anatomical origin of the E18 cells exhibiting chemotaxis or chemokinesis to GABA by assessing the migratory responses of $\mathrm{vz}$ and $\mathrm{cp}$ preparations to each chemotropic GABA concentration.

$\mathrm{Cp}$ cells exhibited significant migration $\left(>50\right.$ cells $\left./ \mathrm{mm}^{2}\right)$ only to micromolar GABA (Fig. $3 A$ ). In contrast, significant numbers of vz cells responded only to the femtomolar GABA concentrations (Fig. $3 A$ ). None of the cells that migrated to GABA had BrdU-labeled nuclei, indicating that only postmitotic cells migrated in response to the attractant. All of the vz cells that responded to femtomolar GABA expressed NF (Fig. 3B); thus, only vz cells of neuronal lineage migrated in response to the attractant. Similarly, all of the cp cells that migrated to GABA were $\mathrm{NF}^{+}$(data not shown). These studies demonstrate that the neuronal populations that migrate to each GABA concentration are derived from distinct anatomical locales.

\section{GAD expression in migrating populations}

Previously, we demonstrated that micromolar GABA stimulates the motility of $\mathrm{GAD}^{+}$cells in dissociates of whole cortex (Behar et al., 1996). In the present study the cp cells responded to micromolar GABA. Thus, we used immunocytochemistry to analyze GAD expression in our starting and migrating preparations of cp cells. Immunostaining revealed that $>90 \%$ of the starting preparation of cp cells was $\mathrm{GAD}^{+}$, and virtually all of the cp cells that migrated to micromolar GABA were $\mathrm{GAD}^{+}$(Fig. 4B,C). In contrast, the majority of cells derived from the whole cortex that migrate to femtomolar GABA in vitro was GAD ${ }^{-}$(Behar et al., 1996). Here, femtomolar GABA induced the vz cells to migrate. Immunostaining of our starting and migrating population of $\mathrm{vZ}$ cells revealed that, whereas nearly $55 \%$ of the starting vz preparation expressed GAD (Fig. 4A,C), <20\% of the migrated vZ neurons was $\mathrm{GAD}^{+}$(Fig. $4 C, D$ ). Thus, the subset of migrated vz cells was relatively enriched in $\mathrm{GAD}^{-}$neurons. These studies demonstrate that each chemotropic concentration of GABA stimulated migration in phenotypically distinct populations of neurons derived from different anatomical regions. Micromolar GABA stimulated the migration of $\mathrm{GAD}^{+}$cells derived from cortical locations associated with mature neurons (the cp preparation), whereas femtomolar GABA induced the migration of predominantly $\mathrm{GAD}^{-}$neurons derived from zones associated with immature cells (the vz dissociates). 

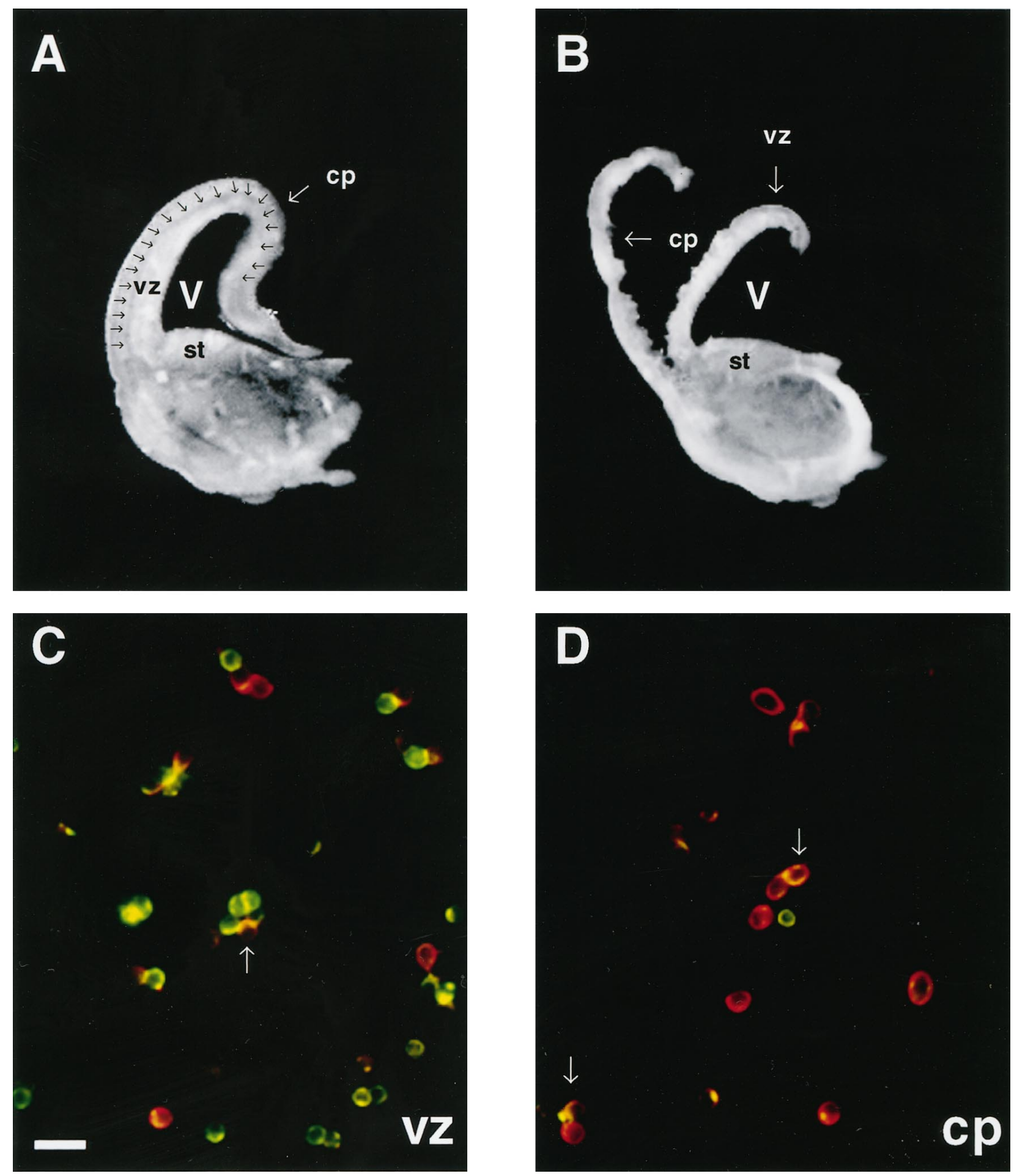

Figure 2. The cortical plate can be microdissected from the ventricular zone in coronal sections of the rat cortex. $A$, A $350 \mu \mathrm{m}$ cross section of one hemisphere from an E18 brain. The intermediate zone (iz, arrows) lies between the cortical plate $(c p)$ and the ventricular zone ( $v z)$. $B$, The cross section has been dissected along the $i z$, resulting in the separation of the $c p$ from the $v z$. Cells in preparations from both regions contain iz cells. $C$, $D$, Photomicrographs of cells from each dissociate are double-labeled for nestin ( green) and TUJ1 (red). C, The majority of cells in the vz preparation labels with anti-nestin antibody. Other TUJ1 ${ }^{+}$cells are scattered throughout the field. $D$, Most cells derived from the cp label with TUJ1, indicating that they are neurons. A minority of cells express nestin only. Arrows in $C$ and $D$ denote newly generated neurons that appear yellow/orange, labeling for both TUJ1 and nestin. st, Striatum; $V$, ventricle. Scale bar in $C, 20 \mu \mathrm{m}$.

\section{GABA promotes motility via PTX-sensitive G-proteins}

Several studies report that the signal transduction mechanisms underlying chemotaxis or chemokinesis in other types of nonneuronal cells involve G-protein activation (Caterina and Dev- reotes, 1991; Amatruda et al., 1993). To analyze the initial signaling mechanisms associated with GABA-induced migration, we preincubated the cells in PTX in some experiments before placing them in the chemotaxis chambers. In the presence of PTX the 


\begin{tabular}{|c|c|c|c|c|c|}
\hline Region & $\begin{array}{l}\text { Total } \\
\text { nestin }^{+}(\%)\end{array}$ & $\begin{array}{l}\text { Total } \\
\text { TUJ1 }^{+}(\%)\end{array}$ & $\begin{array}{l}\text { Nestin }{ }^{+} \\
\text {only }(\%)\end{array}$ & $\begin{array}{l}\text { TUJ1 } 1^{+} \\
\text {only }(\%)\end{array}$ & Both $(\%)$ \\
\hline $\mathrm{vZ}$ & $83.4 \pm 5.2$ & $35.6 \pm 7.3$ & 64.4 & 16.6 & 19.0 \\
\hline$c p$ & $23.2 \pm 5.6$ & $87.7 \pm 1.8$ & 12.4 & 77.0 & 10.7 \\
\hline
\end{tabular}

$n=7$. Characterization of the $\mathrm{vz}$ and $\mathrm{cp}$ dissociates by immunocytochemistry. After dissociation the two populations were double-labeled with anti-nestin and TUJ1 antibodies. The majority of vz cells expresses nestin only (64.4\%), indicating that they are precursor cells. Neurons identified by TUJ1 staining comprise $35.6 \%$ of the $\mathrm{vz}$ population. The majority of cp cells was neurons (87.7\%); only $12.4 \%$ of the $\mathrm{cp}$ cells stained for nestin-only. Values are mean \pm SEM.

vz cell migration to femtomolar GABA and cp cell migration to micromolar GABA were blocked significantly $(92.5 \pm 3.8$ and $63.8 \pm 10.2 \%$, respectively; Fig. 5). In contrast, migration to brain-derived neurotrophic factor (BDNF), which stimulates the motility of embryonic cortical vz neurons via a tyrosine kinase signaling pathway (Meakin and Shooter, 1992; Behar et al., 1997), was not attenuated in the presence of the toxin $(105.9 \pm 6.0 \%)$ (Fig. 5), whereas the alkaloid kinase inhibitor K252a, which blocks tyrosine kinase autophosphorylation, completely blocked BDNF-induced motility $(>95 \pm 1.6 \%)$. K252a did not affect GABA-induced motility (data not shown). These results indicate that the signaling mechanisms associated with the motilitypromoting effects of GABA involve $G_{i} / G_{o}$-protein activation.

\section{Chemoattractant-induced motility is inhibited by depolarizing conditions}

Micromolar concentrations of CACA, a conformationally restricted analog of GABA, mimic the chemotropic effects of micromolar GABA in a subpopulation of embryonic cortical cells (Behar et al., 1996). Only micromolar concentrations of CACA stimulate motility; femtomolar levels fail to induce migration. Because the results of the present study indicate that it is primarily the cp cells that migrate to micromolar GABA, we analyzed the effects of $\mathrm{GABA}_{\mathrm{A}}$ receptor agonists and antagonists on CACA-induced migration of cp cells at E18. The CACA-induced motility was blocked by picrotoxin $(79.8 \pm 9.0 \%)$, but not by the $\mathrm{GABA}_{\mathrm{A}}$ receptor antagonist bicuculline $(333.7 \pm 118 \%)$ (Fig. 6). In fact, in the presence of bicuculline, CACA-induced migration was potentiated threefold, suggesting that when $\mathrm{GABA}_{\mathrm{A}}$ receptors are activated the $\mathrm{cp}$ cell migration is attenuated. To determine whether CACA-induced motility is attenuated when $\mathrm{GABA}_{\mathrm{A}}$ receptors are activated directly, we assessed the migration of cp cells in the presence of $1 \mu \mathrm{M}$ CACA plus $10 \mu \mathrm{M}$ muscimol, a $\mathrm{GABA}_{\mathrm{A}}$ receptor agonist. In the presence of muscimol, cp cell migration to CACA was inhibited $>70 \%(73.6 \pm 9 \%)$ (Fig. 6), providing further evidence that migration is suppressed when $\mathrm{GABA}_{\mathrm{A}}$ receptors are activated. The inhibitory effects of muscimol were abolished in the presence of bicuculline (443.6 \pm $52 \%$ ) (Fig. 6). Because $\mathrm{GABA}_{\mathrm{A}}$ receptor activation depolarizes embryonic neurons (LoTurco et al., 1995), we investigated whether GABA-induced motility is inhibited in the presence of other depolarizing signals.

In the chemotaxis assay, glutamate inhibited GABA-induced migration of cp cells in a dose-dependent manner. High concentrations of glutamate (micromolar) completely attenuated migration, whereas picomolar-nanomolar glutamate failed to inhibit GABA-induced cell movement (data not shown). Similarly, in the presence of elevated $\left[\mathrm{K}^{+}\right]_{\mathrm{o}}$, which would be expected to depolarize cells (LoTurco et al., 1995), cp migration to micromolar
GABA was decreased. In buffer containing $10 \mathrm{~mm} \mathrm{~K}^{+}$, migration was inhibited by $\sim 50 \%$, whereas $15-20 \mathrm{~mm}\left[\mathrm{~K}^{+}\right]_{\mathrm{o}}$ completely blocked GABA-induced motility (Fig. 7A). Similar inhibitory effects were observed when $\mathrm{vz}$ cells migrated to femtomolar GABA in the presence of elevated $\left[\mathrm{K}^{+}\right]_{\mathrm{o}}$ (Fig. $7 B$ ), indicating that depolarization alone can attenuate motility responses of embryonic neurons to GABA. To determine whether depolarization can block the migration of embryonic cortical cells responding to other chemoattractants, we analyzed the effect of increasing concentrations of $\mathrm{K}^{+}$o on BDNF-induced chemotaxis of $\mathrm{vZ}$ cells. In buffer containing $10 \mathrm{mM} \mathrm{K}{ }^{+}$, migration of vz cells to BDNF was decreased by $60 \%$, whereas higher concentrations of $\mathrm{K}^{+}$completely blocked BDNF-induced motility (Fig. 7B). These results demonstrate that, in vitro, even modest elevations in $\mathrm{K}^{+}$ that likely would act to depolarize cells arrest attractant-induced neuronal migration.

\section{DISCUSSION}

We have shown that two phenotypically discrete populations of embryonic cortical neurons, originating from different anatomical locales, migrate in response to distinct concentrations of GABA. PTX, an inhibitor of $G_{i} / G_{o}$-protein activation, suppresses migration in both populations, suggesting that pro-migratory responses to GABA involve the activation of G-proteins and intracellular amplification mechanisms. In contrast, when diverse depolarizing stimuli are present, cell movement is arrested.

\section{Separation of two distinct cortical populations by microdissection}

Our E18 vz preparation contained cells from the vz, svz, and lower iz. Most cells in vz dissociates were nestin ${ }^{+}$, indicating that they were primarily precursors and newly differentiated neurons. The $\mathrm{cp}$ preparation included cells actively migrating through the upper half of the iz, the sp, and lamina IV through VI of the cortical plate (Bayer, 1990). Cells from cp dissociates were predominantly neuronal, as manifested by their TUJ1 immunoreactivity. There was a twofold increase in nestin ${ }^{+}$cells in the vz preparation as compared with a twofold enrichment of TUJ1 ${ }^{+}$ neurons in the $\mathrm{cp}$ dissociates. Thus, the microdissection effectively separated immature cortical cells from more fully differentiated neurons.

The vz and cp populations exhibited unique migratory behavior to GABA. Vz cells primarily responded to femtomolar GABA. None of the migrated vz cells contained BrdU-labeled nuclei, indicating that only postmitotic cells migrated to the attractant. The vz preparation presumably contained other migratory cells types, such as oligodendrocyte precursors, which are reportedly present in the svz at E18 (LeVine and Goldman, 1988). However, only $\mathrm{NF}^{+}$vz cells migrated to GABA, indicating that only cells of neuronal lineage migrated in response to femtomolar GABA. The majority of the migrated vz cells did not express GAD, demonstrating that femtomolar GABA predominantly stimulated the migration of neurons that did not synthesize GABA. Femtomolar GABA stimulates chemotactic movement of embryonic nerve cells in vitro (Behar et al., 1996). In vivo, attractant released by GABAergic cells within the $\mathrm{cp}$ and $\mathrm{sp}$ could diffuse in the interstitial space toward the newly differentiated neurons in the ventricular and subventricular zones. Low levels of GABA encountered by the immature neurons could direct them to migrate toward the cortical plate.

In vivo, the $\mathrm{cp}$ and $\mathrm{sp}$ regions contain GABA-expressing cells at 


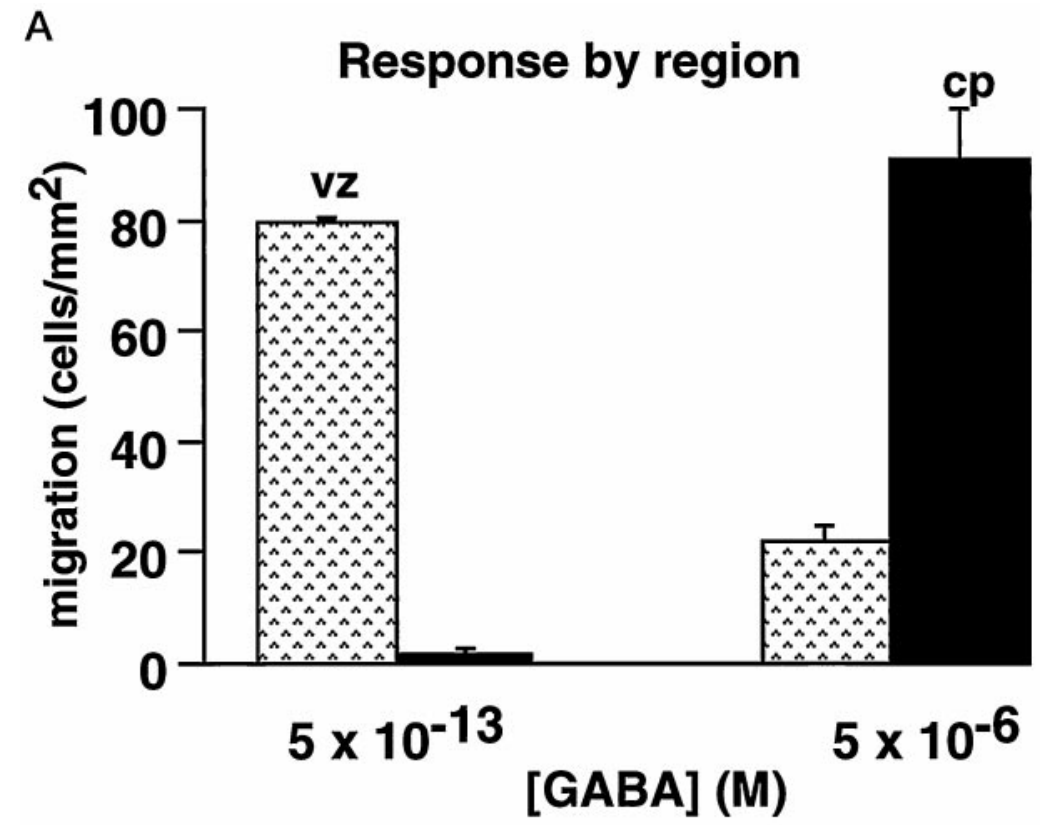

B

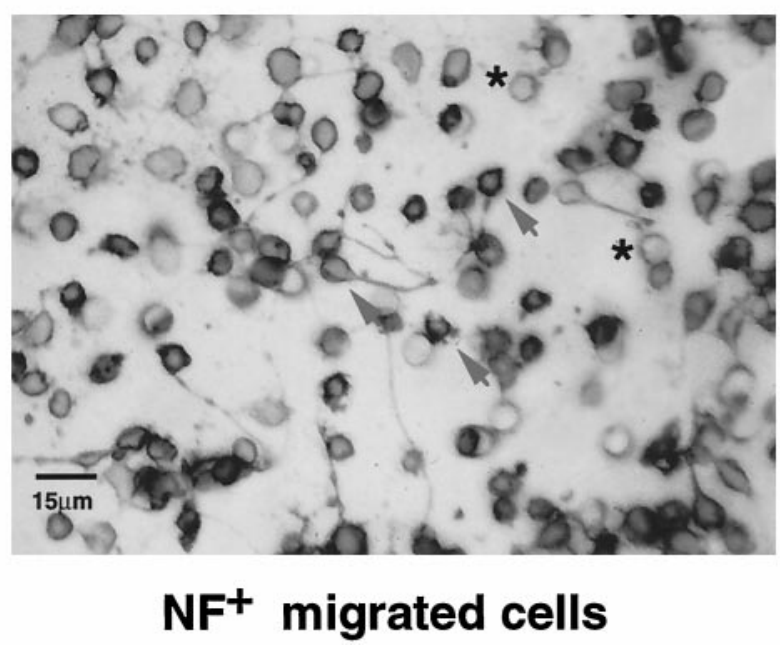

Figure 3. Vz and cp cells migrate to distinct concentration ranges of GABA. $A$, The vz dissociate (圈) responds to the femtomolar range of GABA, whereas the majority of cells in the cp dissociate ( $\square$ ) migrates in response to higher, micromolar levels of GABA. Error bars indicate SEM. B, Photomicrograph of E18 vz cells that were immunoperoxidase-labeled for neurofilament protein after migration to femtomolar GABA. After migration in the chemotaxis assay, the cells were stained with cresyl violet and then immunolabeled for neurofilament protein, using peroxidase-labeled second antibodies, as described in Materials and Methods. All vz cells that migrate to femtomolar GABA in vitro express neurofilament protein (arrows), indicating that they are neurons. Asterisks denote $8 \mu \mathrm{m}$ pores in the membrane. Scale bar, $15 \mu \mathrm{m}$.
E18 (Behar et al., 1996). In the present study E18 cp cells migrated only in response to micromolar GABA, and virtually all responding cp cells expressed GAD. This suggests that, in vivo, GABA stimulates the motility of GABA-containing cp or sp cells, possibly in an autocrine manner (Behar et al., 1996). Because motility to micromolar GABA is chemokinetic (Behar et al., 1996), locally released GABA in these regions may signal the $\mathrm{cp}$ or sp cells to become motile, whereas other factors, as yet unidentified, may provide directional or positional cues.

\section{Stimulation of motility}

The motility-promoting signals of GABA involve the activation of GTP-binding proteins. PTX ADP-ribosylates the $\alpha$-subunit of $\mathrm{G}_{\mathrm{i}}$ and $\mathrm{G}_{\mathrm{o}}$ GTP-binding proteins, inhibiting their activation (Ui, 1984; Ui and Katada, 1990). Here, PTX treatment blocked motility responses of both the vz and cp cells (see Fig. 5). Thus, activation of $\mathrm{G}_{\mathrm{i}^{-}}$or $\mathrm{G}_{\mathrm{o}}$-proteins appears to be one of the steps involved in the signal transduction pathway of GABA-induced motility in most cells. G-protein activation is a common signaling mechanism involved in chemotaxis or chemokinesis of many neuronal and non-neuronal cells (Caterina and Devreotes, 1991;
Amatruda et al., 1993; Sebok et al., 1993; Horgan et al., 1994; Behar et al., 1995). Because G-protein activation is associated with the amplification of signaling mechanisms, it could account for the observed functional response of vz cells to low GABA levels.

In mature neurons, $\mathrm{GABA}_{\mathrm{B}}$ receptors couple to $\mathrm{G}_{\mathrm{i}^{-}}$or $\mathrm{G}_{\mathrm{o}}$ proteins (Kerr and Ong, 1992; Bowery, 1993). R-baclofen, a $\mathrm{GABA}_{\mathrm{B}}$ receptor agonist, mimics the chemotropic effects of GABA on embryonic cortical cells (Behar et al., 1996). Thus, embryonic receptors that promote GABA-induced motility may share signaling mechanisms similar to $\mathrm{GABA}_{\mathrm{B}}$ receptors in mature neurons. Alternatively, GABA binding may stimulate the activation of $\mathrm{G}_{\mathrm{i}^{-}}$or $\mathrm{G}_{\mathrm{o}}$-proteins at a more distal step in the signaling pathway.

Migration to high and low GABA levels was blocked by PTX; however, BDNF-induced motility was unaffected by the toxin. Thus, PTX did not reduce GABA migration by nonspecific actions, such as cell death. In fact, the viability studies demonstrated that the $18 \mathrm{hr}$ incubation in the presence of the toxin did not increase cell death. Chemotactic responses to BDNF are medi- 

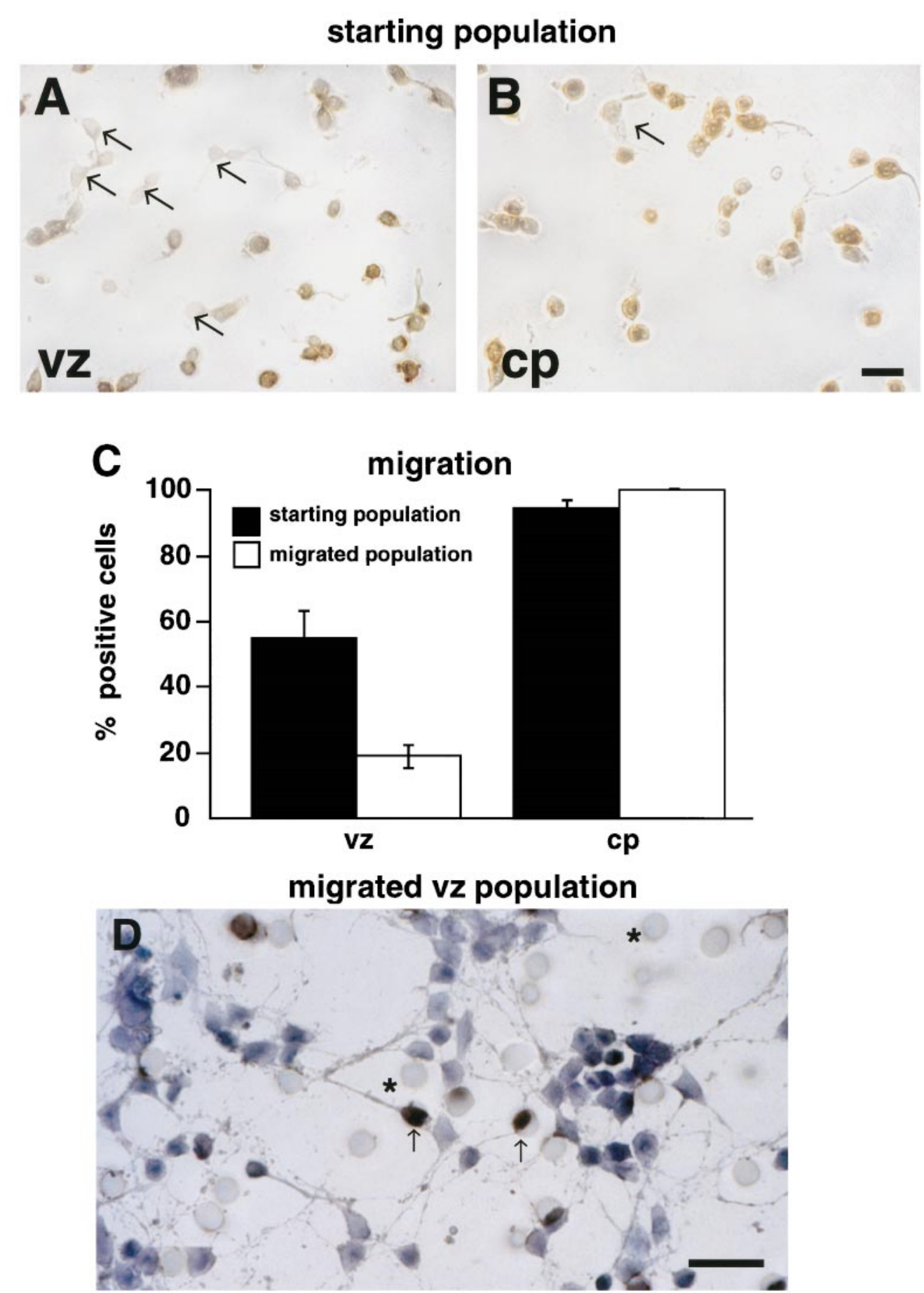

Figure 4. GAD expression in vz and cp cells. $A, B$, Photomicrographs of the vz and cp starting populations immunostained for GAD67. A, Although many cells in the vz dissociate express GAD, unlabeled vz cells are abundant (arrows). $B$, In contrast, nearly all of the cells in the cp dissociate express GAD protein. An arrow highlights an unlabeled cp cell. $C$, Histogram depicting the percentage of GAD ${ }^{+}$cells in the starting ( $\square$ ) versus migrated ( $\square$ ) populations. Nearly $55 \%$ of the starting vz dissociate expresses GAD; however, the majority of vz cells that migrate to femtomolar GABA ( $\sim 82 \%$ ) is $\mathrm{GAD}^{-}$. Most cp cells in the starting population are $\mathrm{GAD}^{+}(>90 \%)$, and all cp cells that migrate to micromolar GABA express GAD. Error bars indicate SEM. $D$, Photomicrograph of migrated vz cells immunostained for GAD67. After migration to femtomolar GABA, vz cells were stained with cresyl violet and then immunolabeled for GAD67 protein, using peroxidase-labeled secondary antibodies. A few migrated vz cells express GAD protein (arrows); most migrated vz cells are unlabeled. Asterisks denote $8 \mu \mathrm{m}$ pores in the membrane. Scale bars in $B$ (also applies to $A$ ), $D: 20 \mu \mathrm{m}$.

ated via TrkB, its high-affinity receptor (Meakin et al., 1992; Behar et al., 1997). The alkaloid kinase inhibitor K252a blocks autophosphorylation of TrkB, one of the early steps in the neurotrophin-signaling pathway. In the present study K252a at- tenuated BDNF-induced motility, whereas PTX failed to suppress BDNF-evoked migration. Thus, the pro-migratory signals of GABA and BDNF differ; GABA stimulates motility via $\mathrm{G}_{\mathrm{i}} /$ $\mathrm{G}_{\mathrm{o}}$-protein activation, whereas BDNF does not. 


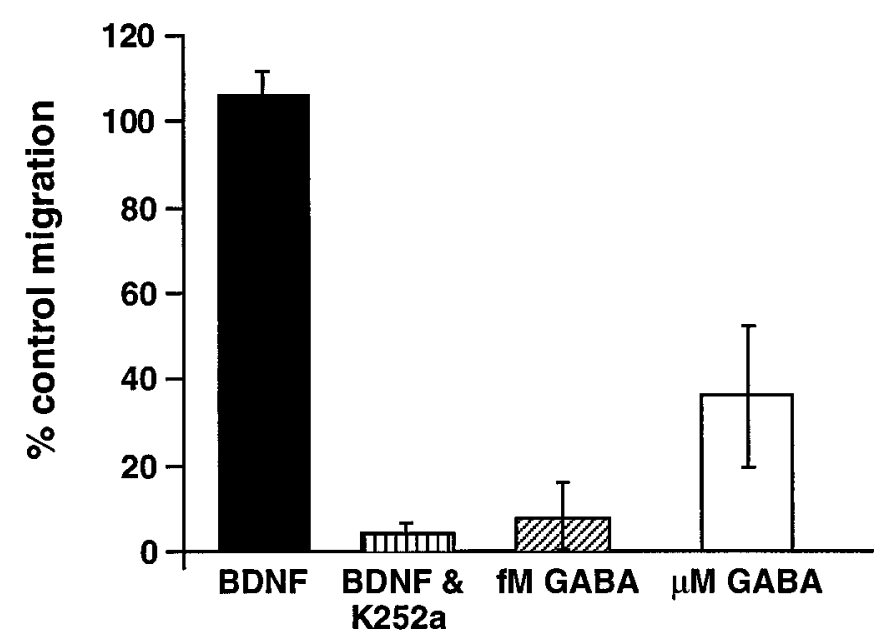

Figure 5. Pertussis toxin treatment selectively blocks in vitro migration to GABA. Treatment with PTX inhibits vz cell migration to GABA $\sim 90 \%$ as compared with control levels. Cp cell responses to micromolar GABA also are inhibited $(>50 \%)$ in the presence of PTX. In contrast, BDNFinduced motility of vz cells is not blocked by PTX treatment; however, K252a, an alkaloid kinase inhibitor, significantly attenuates vZ cell migration to BDNF. Data represent the percentage of the control level of migration averaged from three separate trials. Error bars indicate SEM.

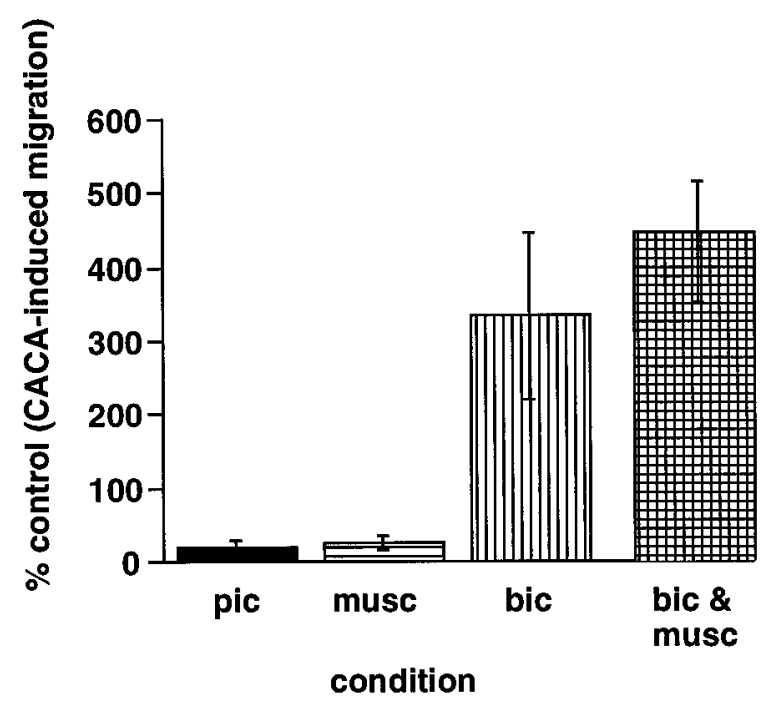

Figure 6. $\mathrm{GABA}_{\mathrm{A}}$ receptor activation arrests in vitro migration. Migration induced by $1 \mu \mathrm{M}$ CACA is inhibited by the activation of $\mathrm{GABA}_{\mathrm{A}}$ receptors with a $10 \mu \mathrm{M}$ concentration of the agonist muscimol (目). Direct inhibition of $\mathrm{GABA}_{\mathrm{A}}$ receptors with a $10 \mu \mathrm{M}$ concentration of the antagonist bicuculline $(\mathbb{W})$ results in a potentiation of migration to CACA. In the presence of a $10 \mu \mathrm{M}$ concentration of both muscimol and bicuculline (国), levels of CACA-induced migration are comparable to migration in the presence of bicuculline only. CACA-induced migration is inhibited in the presence of picrotoxin $(\mathbf{\square})$, which blocks $\mathrm{GABA}_{\mathrm{C}}$ receptors. Data represent the percentage of the control level of migration averaged from multiple trials (muscimol, $n=5$; bicuculline, $n=5$; picrotoxin, $n=5$; muscimol plus bicuculline, $n=3$ ). Error bars indicate SEM.

\section{Inhibition of migration}

Studies on whole cortical dissociates demonstrated that, whereas femtomolar GABA stimulated motility, higher picomolar-nanomolar levels failed to induce migration. The mechanism responsible for the lack of migratory response to these intermediate levels of GABA remains to be resolved. Desensitization of receptors that mediate the motility signals of femtomolar GABA is one
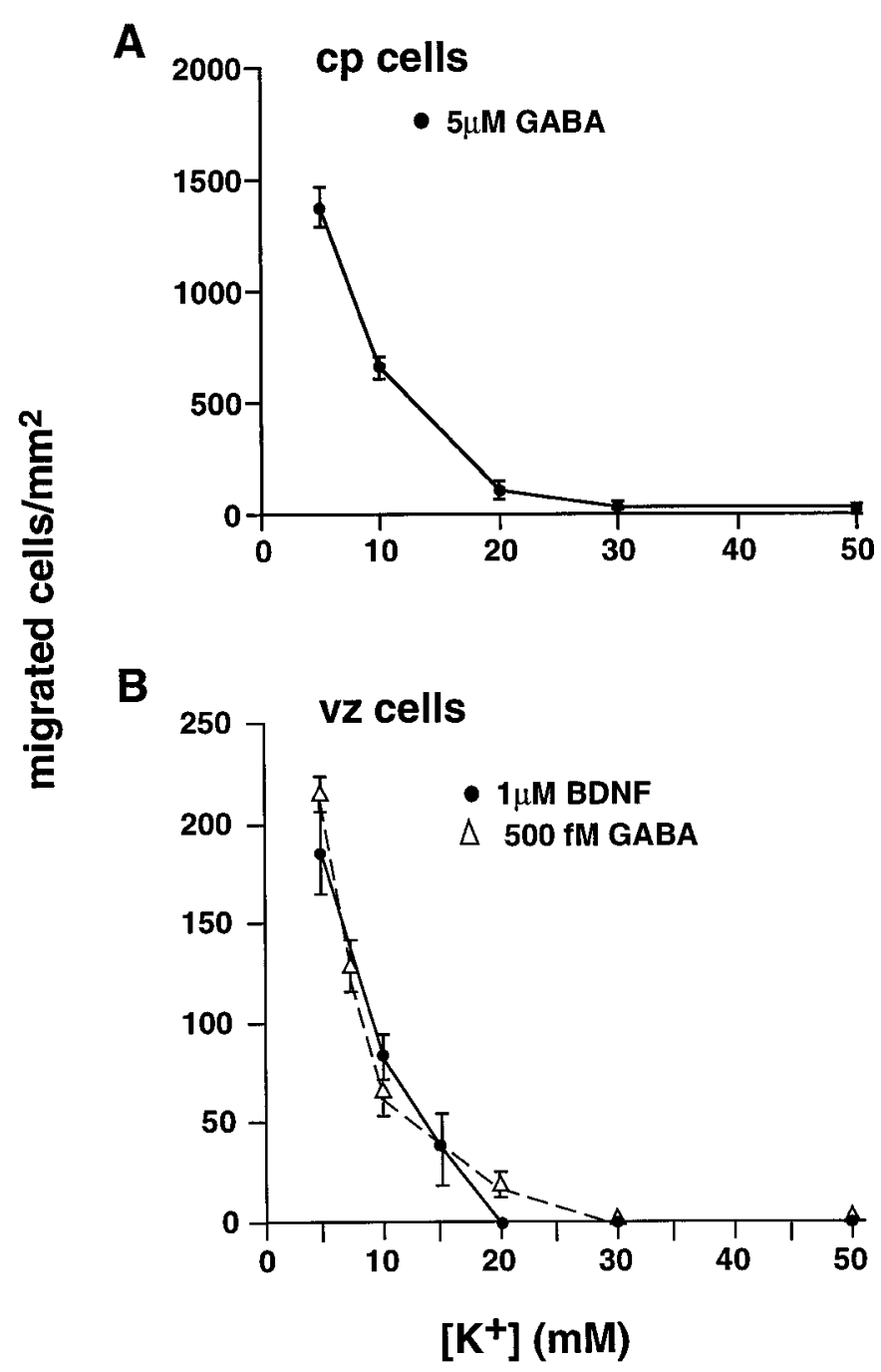

Figure 7. GABA-induced motility is arrested by increased $\left[\mathrm{K}^{+}\right]_{0} \cdot A$, Increasing concentrations of $\left[\mathrm{K}^{+}\right]_{\mathrm{o}}$ attenuate cp cell migration to micromolar GABA. At $10 \mathrm{~mm}\left[\mathrm{~K}^{+}\right]_{\mathrm{o}}$, motility to GABA is inhibited $50 \%$. At $20 \mathrm{~mm}\left[\mathrm{~K}^{+}\right]_{\mathrm{o}}$, migration to GABA is blocked completely. $B$, Femtomolar GABA-induced chemotaxis $(\triangle)$ and BDNF-induced chemotaxis $(\bullet)$ of vz cells are blocked by elevated $\left[\mathrm{K}^{+}\right]_{\mathrm{o}}$. An increase to $10 \mathrm{~mm}\left[\mathrm{~K}^{+}\right]_{\mathrm{o}}$ results in significant inhibition of motility. Higher levels completely block migration. Error bars indicate SEM.

possible explanation. Presumably, the picomolar-nanomolar levels of GABA are not sufficient to activate $\mathrm{GABA}_{\mathrm{A}}$ receptors. However, in the cp cells $\mathrm{GABA}_{\mathrm{A}}$ receptor activation appears to play a role in mediating "stop" signals. Inhibition of $\mathrm{GABA}_{\mathrm{A}}$ receptors with bicuculline resulted in a threefold increase in CACA-induced cp cell migration. In contrast, the migration of $\mathrm{cp}$ cells to CACA was attenuated completely in the presence of the $\mathrm{GABA}_{\mathrm{A}}$ receptor agonist muscimol. These findings suggest that $\mathrm{GABA}_{\mathrm{A}}$ receptor activation may inhibit directly the chemoattractant-induced motility of cp neurons. Cells in the cortical plate primarily express the $\mathrm{GABA}_{\mathrm{A}}$ receptor subunits, $\alpha$ 3, $\beta 3$, and $\gamma 2$ (Maric et al., 1997). Receptors containing these subunits may mediate stop signals for cells migrating within the cortical plate. $\mathrm{GABA}_{\mathrm{A}}$ receptor activation depolarizes embryonic neurons (Walton et al., 1993; Reichling et al., 1994; LoTurco et al., 1995), suggesting that such stimuli serve as stop signals.

In vitro, the excitatory neurotransmitter glutamate suppressed 
GABA-induced motility in a dose-dependent manner. These observations parallel those of Marret et al. (1997), who reported that, in vivo, radial migration of hamster cortical neurons is arrested by activation of ionotropic glutamate receptors (iGlu-R) (Marret et al., 1997).

Activation of $\mathrm{GABA}_{\mathrm{A}}-\mathrm{R}$ and iGlu-R depolarizes embryonic neurons (Walton et al., 1993; LoTurco et al., 1995; Monaghan and Wenthold, 1997). To determine whether membrane depolarization per se also arrests motility, we incubated cells in the presence of attractant plus increased concentrations of $\left[\mathrm{K}^{+}\right]_{\mathrm{o}}$. Migration to GABA or BDNF was attenuated in the presence of modest elevations in $\left[\mathrm{K}^{+}\right]_{\mathrm{o}}(\geq 7.5 \mathrm{~mm})$. Higher $\left[\mathrm{K}^{+}\right]_{\mathrm{o}}$ levels inhibited migration in a concentration-dependent manner, suggesting that membrane depolarization triggers mechanisms that stop cell movement. In vivo, excitatory signals encountered near the target destinations of migrating neurons may be important in signaling approaching cells to stop moving.

These target destinations are in the embryonic cp. Late in gestation the cp contains several sources of excitatory signals. Among these are GABAergic cp cells (Lauder et al., 1986; Behar et al., 1996). In addition, evidence suggests that interstitial $\mathrm{K}^{+}$ may be elevated in the developing cp. Mutani et al. (1974) reported a gradient of interstitial $\mathrm{K}^{+}$ranging from $\sim 3 \mathrm{~mm}$ in the vz to $\sim 35 \mathrm{~mm}$ in the $\mathrm{cp}$ of neonatal rabbits. In the mature CNS, astrocytes remove extracellular $\mathrm{K}^{+}$from regions of synaptic activity. However, during late gestational ages, $\mathrm{cp}$ neurons may be electrically active at a time when astrocytes have not yet developed. Without a "clearing" mechanism, local $\left[\mathrm{K}^{+}\right]_{\mathrm{o}}$ concentrations in the embryonic cp may rise significantly.

The intracellular mechanisms associated with depolarizing signals that inhibit migration remain to be resolved. Cellular locomotion apparently requires fluctuating intracellular $\mathrm{Ca}^{2+}$ levels (Komuro and Rakic, 1992; Hinrichsen, 1993). GABA receptor activation leads to increased $\mathrm{Ca}^{2+}{ }_{\mathrm{c}}$ in embryonic cells, presumably by activating voltage-gated $\mathrm{Ca}^{2+}$ channels (Reichling et al., 1994; LoTurco et al., 1995). However, changes in membrane potential caused by modest elevations in $\left[\mathrm{K}^{+}\right]_{\mathrm{o}}$ effectively halt migration. Such depolarizations would not be expected to activate voltage-gated $\mathrm{Ca}^{2+}$ channels. Interestingly, Deák et al. (1997) recently described a $\mathrm{Ca}^{2+}$ current in cultured hippocampal neurons $\left(I_{\mathrm{g} 1}\right)$ that is activated after modest elevations (5-10 $\mathrm{mm}$ ) in $\left[\mathrm{K}^{+}\right]_{\mathrm{o}}$ (Várnai et al., 1995; Deák et al., 1997). A similar $\mathrm{K}^{+}$-sensitive $\mathrm{Ca}^{2+}$ conductance may exist in immature cortical neurons. Because $\mathrm{Ca}^{2+}{ }_{\mathrm{c}}$ levels are instrumental in mediating motility (Hinrichsen, 1993; Behar et al., 1996; Komuro and Rakic, 1996), the stop signals associated with migration may involve a modulation of $\mathrm{Ca}^{2+}{ }_{\mathrm{c}}$ levels that alters the dynamics of cytoskeletal remodeling underlying cell movement.

We have shown that GABA is capable of both stimulating and arresting the migration of embryonic cortical neurons via different signaling mechanisms and GABA-R. Although pro-migratory responses to GABA involve PTX-sensitive G-protein activation, cellular movement induced by GABA is arrested by depolarization. Similarly, depolarization arrests embryonic cortical cell chemotaxis to BDNF, suggesting that this mechanism serves as a universal stop signal for migratory neurons within the developing CNS.

\section{REFERENCES}

Amatruda TT, Gerard NP, Gerard C, Simon MI (1993) Specific interactions of chemoattractant factor receptors with G-proteins. J Biol Chem 268:10139-10144.
Armstrong RC, Harvath L, Dubois-Dalcq M (1990) Type 1 astrocytes and oligodendrocyte-type 2 astrocyte glial progenitors migrate toward distinct molecules. J Neurosci Res 27:400-407.

Bayer SA (1990) Development of the lateral and medial limbic cortices in the rat in relation to cortical phylogeny. Exp Neurol 107:118-131.

Behar TN, Schaffner AE, Colton CA, Somogyi R, Olah Z, Lehel C, Barker JL (1994) GABA-induced chemokinesis and NGF-induced chemotaxis of embryonic spinal cord neurons. J Neurosci 14:29-38.

Behar TN, Schaffner A, Tran H, Barker J (1995) GABA-induced motility of spinal neuroblasts develops along a ventrodorsal gradient and can be mimicked by agonists of $\mathrm{GABA}_{\mathrm{A}}$ and $\mathrm{GABA}_{\mathrm{B}}$ receptors. J Neurosci Res 42:97-108.

Behar TN, Li YX, Tran HT, Ma W, Dunlap V, Scott C, Barker JL (1996) GABA stimulates chemotaxis and chemokinesis of embryonic cortical neurons via calcium-dependent mechanisms. J Neurosci 16:1808-1818.

Behar TN, Dugich-Djordjevic MM, Li Y-X, Ma W, Somogyi R, Wen X, Brown E, Scott C, McKay RDG, Barker JL (1997) Neurotrophins stimulate chemotaxis of embryonic cortical neurons. Eur J Neurosci 9:2561-2570.

Bowery NG (1993) GABA $_{\mathrm{B}}$ receptor pharmacology. Annu Rev Pharmacol Toxicol 33:109-147.

Caterina MJ, Devreotes PN (1991) Molecular insights into eukaryotic chemotaxis. FASEB J 5:3078-3085.

Deák F, Nagy G, Várnai P, Spat A (1997) Non-voltage-operated calcium current $\left(I_{\mathrm{g} 1}\right)$ activated by potassium ions in rat hippocampal pyramidal neurons. J Physiol (Lond) 501:31P.

Frantz GD, McConnell SK (1996) Restriction of late cerebral cortical progenitors to an upper-layer fate. Neuron 17:55-61.

Geiser T, Dewald B, Ehrengruber MU, Clark LI, Baggiolini M (1993) The interleukin-8-related chemotactic cytokines GRO alpha, GRO beta, and GRO gamma activate human neutrophil and basophil leukocytes. J Biol Chem 268:15419-15424.

Harvath L, Falk W, Leonard EJ (1980) Rapid quantitation of neutrophil chemotaxis: use of a polyvinylpyrrolidone-free polycarbonate membrane in a multiwell assembly. J Immunol Methods 37:39-45.

Higashiyama S, Abraham JA, Klagsbrun M (1993) Heparin-binding EGF-like growth factor stimulation of smooth muscle cell migration: dependence on interactions with cell surface heparan sulfate. J Cell Biol 122:933-940.

Hinrichsen RD (1993) Calcium and calmodulin in the control of cellular behavior and motility. Biochim Biophys Acta 1155:277-293.

Horgan AM, Lagrange MT, Copenhaver PF (1994) Developmental expression of G-proteins in a migratory population of embryonic neurons. Development 120:729-742.

Jacobson M (1991) Developmental neurobiology, 3rd Ed. New York: Plenum.

Kerr DIB, Ong J (1992) GABA agonists and antagonists. Med Res Rev 12:593-636.

Komuro H, Rakic P (1992) Selective role of N-type calcium channels in neuronal migration. Science 257:806-809.

Komuro H, Rakic P (1996) Intracellular $\mathrm{Ca}^{2+}$ fluctuations modulate the rate of neuronal migration. Neuron 17:275-285.

Lauder JM, Han VKM, Henderson P, Verdoorn T, Towle AC (1986) Prenatal ontogeny of the GABAergic system in the rat brain: an immunocytochemical study. Neuroscience 19:465-493.

Lee MK, Tuttle JB, Rebhun L, Cleveland D, Frankfurter A (1990) The expression and posttranslational modification of a neuron-specific $\beta$-tubulin isotype during chick embryogenesis. Cell Motil Cytoskeleton 17:118-132.

LeVine SM, Goldman JE (1988) Spatial and temporal patterns of oligodendrocyte differentiation in rat cerebrum and cerebellum. J Comp Neurol 277:441-455.

LoTurco JJ, Owens DF, Heath MJ, Davis MB, Kriegstein AR (1995) GABA and glutamate depolarize cortical progenitor cells and inhibit DNA synthesis. Neuron 15:1287-1298.

Ma W, Behar T, Barker J (1992) Transient expression of GABA immunoreactivity in the developing rat spinal cord. J Comp Neurol 325:271-290.

Maric D, Maric I, Ma W, Lahojuji F, Somogyi R, Wen X, Sieghart W, Fritschy JM, Barker JL (1997) Anatomical gradients in proliferation and differentiation of embryonic rat CNS accessed by buoyant density fractionation: $\alpha 3, \beta 3$, and $\gamma 2 \mathrm{GABA}_{\mathrm{A}}$ receptor subunit coexpression by postmitotic neocortical neurons correlates directly with cell buoyancy. Eur J Neurosci 9:507-522.

Marret S, Gressens P, Evrard P (1997) Arrest of neuronal migration by 
excitatory amino acids in hamster developing brain. Proc Natl Acad Sci USA 93:15463-15468.

Meakin SO, Shooter EM (1992) The nerve growth factor family of receptors. Trends Neurosci 15:323-331.

Meakin SO, Suter U, Drinkwater CC, Welcher AA, Shooter EM (1992) The rat trk proto-oncogene product exhibits properties characteristic of the slow nerve growth factor receptor. Proc Natl Acad Sci USA 89:2374-2378.

Monaghan DT, Wenthold RJ (1997) The ionotropic glutamate receptors. Totowa, NJ: Humana.

Mutani R, Futamachi KJ, Prince DA (1974) Potassium activity in immature cortex. Brain Res 75:27-39.

Reichling DB, Kyrozis A, Wang J, MacDermott AB (1994) Mechanisms of GABA and glycine depolarization-induced calcium transients in rat dorsal horn neurons. J Physiol (Lond) 476:411-421.

Schaffner A, Behar T, Nadi S, Barker JL (1993) Quantitative analysis of transient GABA expression in embryonic and early postnatal rat spinal cord neurons. Dev Brain Res 72:265-276.

Sebok K, Woodside D, al-Aoukaty A, Ho AD, Gluck S, Maghazachi AA
(1993) IL-8 induces the locomotion of human IL-2 activated natural killer cells. Involvement of a guanine nucleotide binding $\left(G_{o}\right)$ protein. J Immunol 150:1524-1534.

Tohyama T, Lee V, Rorke L, Marvin M, McKay R, Trojanowski J (1992) Nestin expression in embryonic human neuroepithelium and in human neuroepithelial tumor cells. Lab Invest 66:303-313.

Ui M (1984) Islet-activating protein, pertussis toxin: a probe for functions of the inhibitory guanine nucleotide regulatory component of adenylate cyclase. Trends Pharmacol Sci 5:277-279.

Ui M, Katada T (1990) Bacterial toxins as probe for receptor- $\mathrm{G}_{\mathrm{i}}$ coupling. Adv Second Messenger Phosphoprotein Res 24:63-69.

Várnai P, Osipenko ON, Vizi ES, Spat A (1995) Activation of calcium current in voltage-clamped rat glomerulosa cells by potassium ions. J Physiol (Lond) 15:67-78.

Walton MK, Schaffner AE, Barker JL (1993) Sodium channels, GABA receptors, and glutamate receptors develop sequentially on embryonic rat spinal cord cells. J Neurosci 13:2068-2084.

Yao J, Gilbert D, Colton C (1990) Chemotaxis of cultured CNS microglia. J Neurosci Res 27:36-42. 